\title{
BMJ Open Deployment experiences and mental health problems as predictors of post- deployment unemployment length: a prospective, register-based study among Danish soldiers
}

\author{
Andreas Friis Elrond (D) , ${ }^{1,2}$ Paul Maurice Conway, ${ }^{2}$ Søren Bo Andersen, ${ }^{1}$ \\ Karen-Inge Karstoft, ${ }^{1,2}$ Mia Sadowa Vedtofte, ${ }^{1}$ Jacob Pedersen ${ }^{3}$
}

To cite: Elrond AF, Conway PM, Andersen SB, et al. Deployment experiences and mental health problems as predictors of postdeployment unemployment length: a prospective, register-based study among Danish soldiers. BMJ Open 2020;10:e040625. doi:10.1136/ bmjopen-2020-040625

- Prepublication history for this paper is available online. To view these files, please visit the journal online (http://dx.doi. org/10.1136/bmjopen-2020040625).

Received 18 May 2020

Revised 11 August 2020

Accepted 03 November 2020

Check for updates

(C) Author(s) (or their employer(s)) 2020. Re-use permitted under CC BY-NC. No commercial re-use. See rights and permissions. Published by BMJ.

${ }^{1}$ Research and Knowledge Centre, Danish Veteran Centre, Ringsted, Denmark

${ }^{2}$ Department of Psychology, University of Copenhagen, Faculty of Social Sciences, Copenhagen, Denmark ${ }^{3}$ National Research Centre for the Working Environment Copenhagen, Denmark

Correspondence to Mr Andreas Friis Elrond; andreas.elrond@psy.ku.dk

\section{ABSTRACT}

Objectives To test responses of formerly deployed soldiers (FDS) to a questionnaire on deployment experiences in combination with screening levels of post-traumatic stress disorder (PTSD) and depression approximately 6 months after homecoming as predictors of the subsequent probability of gaining employment when unemployed within 5 years post-deployment.

Design, setting and participants Danish FDS responders $(\mathrm{n}=3935)$ and non-responders $(\mathrm{n}=3046)$ to a 6 -month post-deployment screening questionnaire after returning from a first-ever deployment to Kosovo, Iraq or Afghanistan (2002 to 2012) were included in the study and followed in public registers from 6 months to 5 years postdeployment.

Primary and secondary outcome measures We tested Cox regression models including deployment experiences (1a), screening levels of PTSD and depressive symptoms (1b), and their combination (2) for FDS responders. For all FDS, a secondary model included a measure on whether they responded to the questionnaire (3).

Results Neither the deployment experiences (1a) of exposure to danger and combat $(\mathrm{HR}=1.00,95 \% \mathrm{Cl}=0.97$ to 1.03) and witnessing consequences of war ( $\mathrm{HR}=1.01$, $95 \% \mathrm{Cl}=0.96$ to 1.06 ), or the screening levels (1b) of PTSD ( $\mathrm{HR}=1.06,95 \% \mathrm{Cl}=0.84$ to 1.33 ) and depressive symptoms ( $\mathrm{HR}=0.82,95 \% \mathrm{Cl}=0.64$ to 1.06 ) were significant predictors of transitioning from unemployment to employment. Similar results were found for the combined model (2). A tendency among non-respondents (3) to have a lower probability of transitioning from unemployment to employment was found $(\mathrm{HR}=0.90,95 \%$ $\mathrm{Cl}=0.81$ to 1.00).

Conclusion Deployment experiences, PTSD and depressive symptoms, as measured at 6-month screening questionnaire, did not predict differences in the probability of gaining employment when unemployed within 5 years post-deployment. However, the findings suggest that those with the least probability of transitioning from unemployment to employment can be found among the non-responders to the post-deployment screening questionnaire.

\section{Strengths and limitations of this study}

- This study accounted for previous methodological limitations in the field by using a registry-based outcome to assess the exact time in unemployment before gaining employment, while using validated scales from a systematically deployed screening questionnaire to account for deployment experiences, and post-traumatic stress disorder and depressive symptoms.

- The use of registries allowed for the relation between non-response to the screening questionnaire and the chance of gaining employment when unemployed to be tested separately.

- The setup, however, did not allow to control for the effects of mental health treatment based on the results of the screening questionnaire, or for incorporating information on the reason for soldiers to separate from the defence before the unemployment.

\section{INTRODUCTION}

The ability of formerly deployed soldiers (FDS) to gain employment after leaving the armed forces remains an area of interest and concern. Identification of factors predictive of employment problems may provide the possibility of identifying and targeting FDS in need of aid to secure a foothold in the labour market. Studies have suggested post-traumatic stress disorder (PTSD) ${ }^{1-5}$ and depression, ${ }^{4-10}$ independently and in combination, ${ }^{9} 11$ to be related to higher levels of post-deployment unemployment and nonemployment in soldier populations, and to have an effect on the ability of FDS to work and function to their full capabilities. ${ }^{2} 12-15$ However, several other studies have found PTSD $^{6-8111314}$ and depression ${ }^{8111314}$ to have no or a limited relationship to subsequent 
unemployment for FDS. Depletion in functioning ${ }^{14}$ and lack of trust in one's ability to gain employment ${ }^{2}{ }^{10}$ rather than a complete inability to work have been suggested as the consequence of PTSD and depression. This may affect those who are unemployed and looking for employment. Research into the effects of deployment on unemployment, independent and beyond the effects of PTSD and depression, remains limited, with studies both supporting $^{1316} 17$ and not supporting ${ }^{8} 18$ a relationship. However, no study has previously examined the effects of deployment experiences and PTSD or depressive symptoms as predictors of transitioning from unemployment to employment in FDS.

Previous research presents a series of methodological issues that limit conclusions about the ability of FDS to gain employment. Differences in results across employment studies may, among other factors, be attributed to considerable variation in duration and timing of post-deployment symptom assessments. ${ }^{19}$ Moreover, the timing of the employment outcomes (ranging from days to years), ${ }^{1620}$ as well as disparity of the underlying periods ${ }^{1620}$ may affect the results. The widespread use of cross-sectional data or data from treatment-seeking and help-seeking veteran populations further limits the possibility of drawing conclusions about causal relationships between deployment experiences, mental health problems and post-deployment employment. ${ }^{2122}$ Non-response to predominantly voluntary screening programmes is high, ${ }^{23}$ and has been related to poorer mental health outcomes. ${ }^{24}{ }^{25}$ Finally, the use of a single-point follow-up, which only allows for dichotomous outcome categories (eg, unemployed versus employed), does not allow for the study of transitions of FDS in the labour market.

Against this background, the primary aim of this study was to investigate deployment experiences as well as PTSD and depressive symptoms at screening as predictors of gaining employment when unemployed, from 6 months to 5 years after the first-ever military deployment. To this end, we used a systematically distributed screening questionnaire and national register data on employment status. Given a non-response rate of $43 \%$ of the identified population, a secondary aim was to investigate nonresponse to the questionnaire as a predictor of gaining employment when unemployed.

\section{METHOD}

\section{Data}

We used the deployment database of the Danish Veteran Centre $^{26}$ to identify period and country of deployment as well as previous deployments. From the Danish Veteran Centre, we obtained data from self-report questionnaires on Psychological Reactions following International Missions (PRIM). PRIM has been routinely distributed by personal mail since 1998 to Danish FDS approximately 6 months after homecoming to assess deployment experiences and post-deployment reactions in order to identify those in need of support by military psychologists.
PRIM consists of 125 individual items covering deployment experiences, post-deployment reactions and postdeployment support, as well as five validated scales, here among PTSD and depression symptoms as well as deployment experiences (see 'Predictors' below for included items and scales). The questionnaire has an average response rate of $60 \%$ across all deployments. ${ }^{27}$ Data on labour market transitions came from the Danish Register for Evaluation of Marginalisation (DREAM), which contains weekly records of social benefit payments for all Danes since $1991 .^{28}$ All data were hosted by Statistics Denmark and linked via a unique personal identification number, and the analyses were conducted on de-identified records on servers of Statistics Denmark. Due to the low rates of missing data, we excluded participants if they had missing data on any of the selected measures.

\section{Population and procedure}

We included FDS who had a single deployment to Kosovo, Iraq or Afghanistan from 2002 to 2012 (see figure 1 for attrition). Of 10974 FDS deployed to one of these countries and during the period of interest, 2550 were excluded due to having previous deployments, and 633 for being deployed again before the follow-up period 6 months after the first homecoming. This was done to exclude potential effects of previous or subsequent deployment experiences. In addition, $3348(43.0 \%)$ did not have a corresponding PRIM record, while the correct record could not be identified in 18 cases. In the study period, the Danish defence used temporary contracts or permanent contracts that terminate at 36 (or 60) years of age. The contract terminating at age 36 includes the possibility for subsequently taking civilian education for a period while still getting wage by the defence. To avoid possible systematic bias at 36 years of age, we further excluded 275 FDS that were age 36 or older at the start of follow-up or that were otherwise censored (eg, deceased). Finally, 215 FDS were excluded for having missing data on the PRIM questionnaire used in the study. This resulted in a final sample of 3935 for the primary analysis. The secondary analysis included 3046 non-responders of PRIM who otherwise met the follow-up criteria just specified.

\section{Patient and public involvement}

No patients involved. As the study was conducted on de-identified data, the FDS included in this study were not directly involved in shaping the research question, methods or dissemination. The results will be disseminated through the Danish Veteran Centre, which is a public institution formed to support and inform work with the population.

\section{Measures}

Unemployment periods and employment

Unemployment periods were identified based on information on weekly payments of unemployment benefits from the DREAM register. We identified periods of employment as periods without any social payments. We 


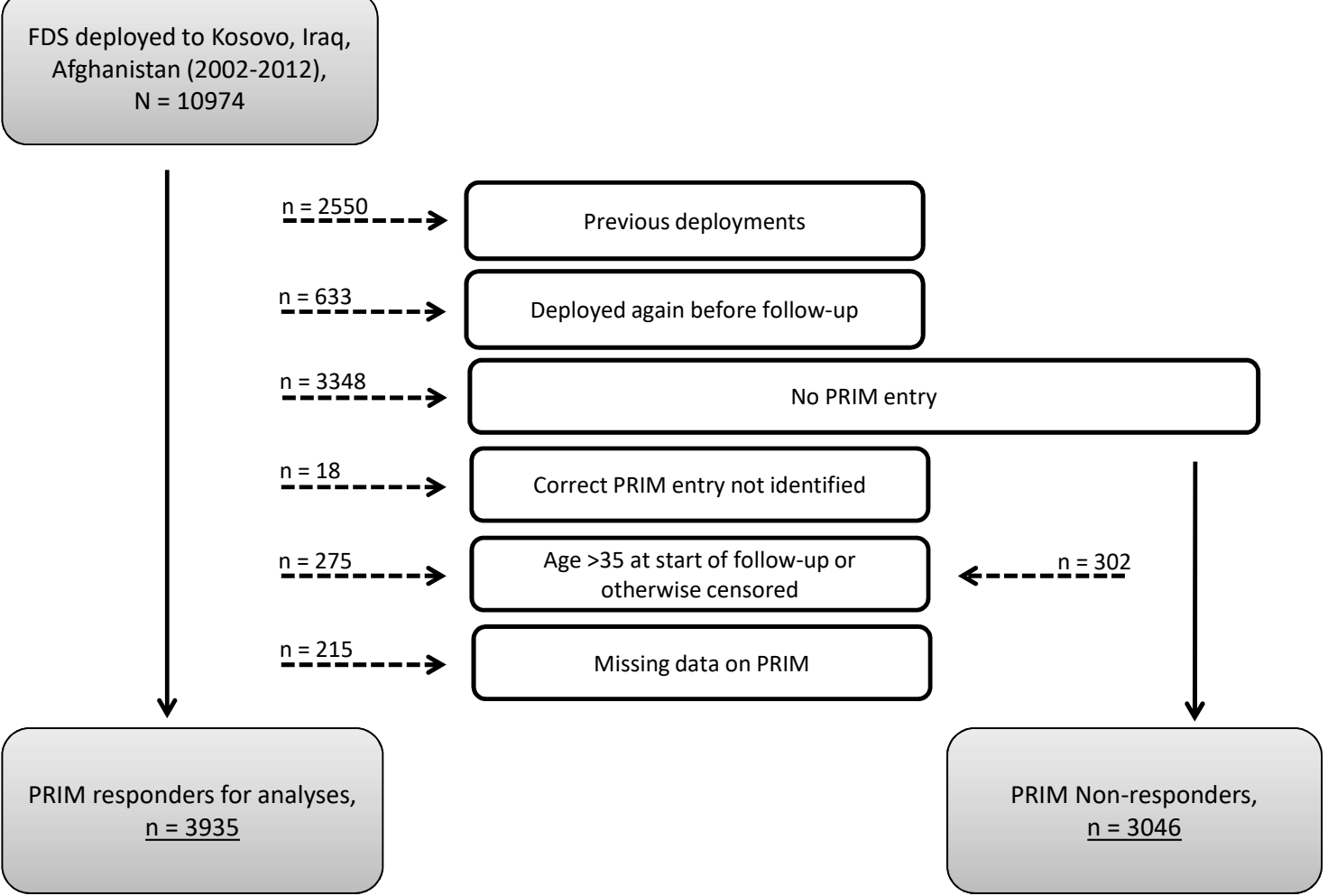

Figure 1. Fall-out of formerly deployed soldiers until follow-up, responders and non-responders.

FDS = Formerly Deployed Soldiers; PRIM = Psychological Reactions following International

Missions (Questionnaire).

Figure 1 Fall-out of FDS until follow-up, responders and non-responders. FDS, formerly deployed soldiers; PRIM, Psychological Reactions following International Missions (questionnaire).

included all periods of unemployment into the study and counted all unemployment periods immediately succeeded by an employment period as a transition/ event. Periods of other social payments like sickness absence, education benefits were censored.

\section{Predictors}

From the PRIM questionnaire, we included the PRIMPTSD scale in which scores range from 12 to 48 and the cut-off score of 24.5 is used to screen for possible PTSD (No-PTSD/Possible PTSD). The PRIM-PTSD and the cut-off score have previously been validated. ${ }^{27}$ We also included the eight-item PRIM Depression scale, which has been validated and shown to be reliable across cohorts. ${ }^{29}$ Scores range from 0 to 8 and a previously established cutoff score of 6 is used to screen for depression. ${ }^{30}$ From PRIM we also included the Rasch validated Exposure to Danger and Combat Scale (EDCS) and the Witnessing Consequences of War Scale (WCWS) to account for exposure to adverse deployment experiences. EDCS scores range from 6 to 24 and WCWS scores range from 4 to $16,{ }^{31}$ with higher scores indicating a more dangerous environment.
Finally, for the secondary analysis, we included a binary variable indicating response or non-response to the PRIM questionnaire.

From the registers, we included information on gender and time-dependent information on age group (18 to 24 and 25 to 35 ), highest achieved education (short/preparatory and longer/vocational). Finally, we included information on habitation in the five geographical regions of Denmark to account for any regional differences in the chance of gaining employment (eg, between the Capital region and other less dense regions).

\section{Statistical analyses}

Initial analyses tested the differences in the probability of having a period of unemployment, in relation to PTSD and depression symptoms, using $\chi^{2}$ test. The prospective association of deployment experiences and mental health problems assessed in PRIM, and response to PRIM with subsequent unemployment-employment transitions was examined with a four-step Cox regression model. ${ }^{32} 33$

We modelled the probability of transitioning from unemployment to employment with the timeline being 
the days from 6 months to 5 years post-deployment, and the possibility of late entry (ie, entering the model later than at 6 months exactly). FDS were allowed to have multiple and recurrent unemployment periods and individual variance was accounted for by including a frailty model. $^{32}{ }^{34}$ Soldiers were right-censored if they redeployed, received a disability pension, died or had turned 36 years of age and thus could have their contract terminated. FDS were treated as being temporarily censored from the model, with the possibility of re-entering, when they were not receiving unemployment benefits or if they had emigrated. We adjusted for changes in employment rates, by dividing the follow-up period into the four time periods: 2002 to 2005, 2006 to 2009, 2010 to 2013 and 2014 to 2017, in which the employment rates were fairly stable. ${ }^{35}$ We stratified the Cox regression by each period, which allowed for separate baseline hazards in each time period.

Model 1a included the war exposure scales EDCS and WCWS. Model 1b included the variables assessing possible PTSD and depression at the 6-month follow-up. As the questionnaire measures were given only once to each individual, it was not possible to model a possible mediating relationship between experiences, mental health problems and the probability of employment; however, model 2 included all variables of model 1a and $1 b$ to test if experiences had a unique effect on unemployment length after mental health was factored in. Finally, a second analysis was conducted, including the large proportion of individuals that did not have a PRIM response, and the follow-up response model 3 included an indicator of response or non-response to test the effect of not responding to the PRIM. All models were adjusted for gender, age group and region of habitation, and were further stratified by periods of similar employment rates and education level. The proportional hazard assumption of the predictors in the four models was evaluated and found acceptable by the use of scaled Schoenfeld residuals through the survival package in $\mathrm{R} .{ }^{36}$ Education level was included as a second stratifying variable as it did not meet the proportional hazard assumption.

A supplementary analysis introduced PTSD and depressive symptoms, which are known to correlate, ${ }^{37}$ separately into the models. Furthermore, we conducted a supplementary analysis of the interaction of PTSD and depressive symptoms that has previously been found elsewhere. ${ }^{11}$ Finally, as lower symptomatology has been previously shown to have weaker association with employment problems, ${ }^{2}{ }^{15}$ we also tested the models using stricter established cut-offs corresponding to a probable PTSD and depression diagnosis (29.5 and 7, respectively) $)^{27} 2930$ as a sensitivity analysis.

All analyses were performed using base R (V.3.5.1) and the R Survival package (V.2.43.1). ${ }^{36}$
RESULTS

Table 1 shows the baseline characteristics of the FDS population at the beginning of the follow-up period. Most of the first-ever deployments were to Kosovo and fewest were to Iraq, with Afghanistan being in between. The majority of FDS were male, and at the beginning of follow-up, the majority were between 18 and 24 years old and had a preparatory or low level of education. Furthermore, $9.9 \%$ met the screening criteria for PTSD, and $8.7 \%$ the screening criteria for depression.

Of the 3935 FDS included, $947(24.1 \%)$ had at least one unemployment period, and of these, $824(86.9 \%)$ FDS were re-employed within the follow-up period. The proportion having an unemployment period was significantly higher for the group that screened positive for PTSD $(34.5 \%)$ than for the group that did not $(22.9 \%)$ $\left(\chi^{2}(1)=25.22, p<0.001\right)$. Similar results were found for those who screened positive for depression $(33.1 \%)$ compared with those who did not $(23.2 \%)\left(\chi^{2}(1)=16.32\right.$, $\mathrm{p}<0.001)$.

The results of the four Cox regression models can be seen in table 2. Deployment experiences included in model la were not predictive of obtaining employment when unemployed. The mental health predictors in model $1 \mathrm{~b}$ yielded similar results, as none of these variables predicted transition into employment. As a result of this, none of the variables were significant predictors when included in the adjusted model 2. The final model 3 testing non-response as a predictor, found that non-responders bordered on a significantly lower probability of gaining employment $(\mathrm{HR}=0.90,95 \% \mathrm{CI}=0.81$ to $1.00)$. In this model, higher age was related with a significantly lower chance of gaining employment $(\mathrm{HR}=0.87$, $95 \% \mathrm{CI}=0.78$ to 0.98$)$.

The supplementary analyses, introducing PTSD and depressive symptoms separately into the model, testing their interaction and using stricter established cut-offs, did not change the non-significant finding (results not shown).

\section{DISCUSSION}

This study assessed experiences during military deployment and screening levels of PTSD and depression as predictors of differences in the probability of transitioning from unemployment to employment among FDS under the age of 36 who had experienced one deployment only. The descriptive analyses suggested that FDS with screening levels of PTSD or depression had a higher probability of experiencing at least one unemployment period during follow-up. However, no significant associations were found between experiences during military deployment and screening levels of PTSD and depression, and the probability of becoming employed in the period considered in any of the models. The secondary analysis that tested response to the follow-up questionnaire at approximately 6 months found that non-response bordered on having a relationship with a 
Table 1 FDS population characteristics at the start of follow-up time (6 months after homecoming)

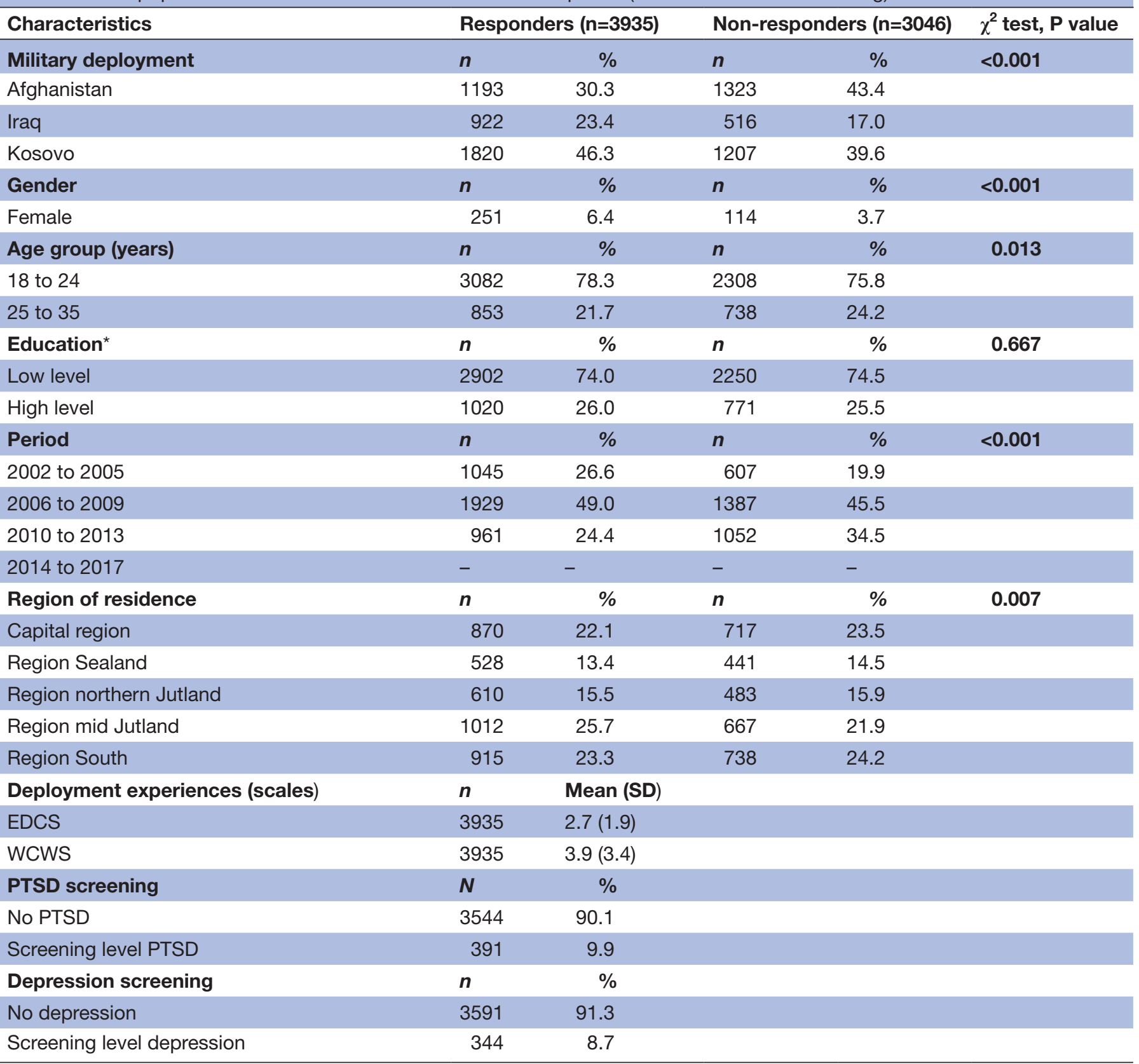

${ }^{*}$ No information on education at beginning of follow-up for 13 FDS.

EDCS, Exposure to Danger and Combat Scale; FDS, formerly deployed soldiers; PTSD, post-traumatic stress disorder; WCWS, Witnessing Consequences of War Scale.

lower chance of gaining employment. Higher age was, in this analysis, significantly related with a lowered risk of gaining employment. These results did take into account the periodic changes in the underlying chance of gaining employment throughout the time span (2002 to 2017), for example, during the financial crisis. To the best of our knowledge, this is the first study to use exact register-based outcome periods to evaluate the effect of deployment experiences and mental health problems on subsequent labour market transitioning outside of a treatment-seeking population.
Strengths and limitations

The present study has several methodological strengths, which advance methodological limitations of previous research. In particular, this study was based on biasfree outcomes assessed in register data, including the exact periods of unemployment before transitioning to employment as well as background characteristics. The objective nature of the outcome enabling us to keep track of individual employment data on a week-to-week basis, counteracts problems with recall bias or bias relating to differences in risk as result of differences in follow-up 
Table 2 Cox regression models of HRs for transitioning from unemployment to employment

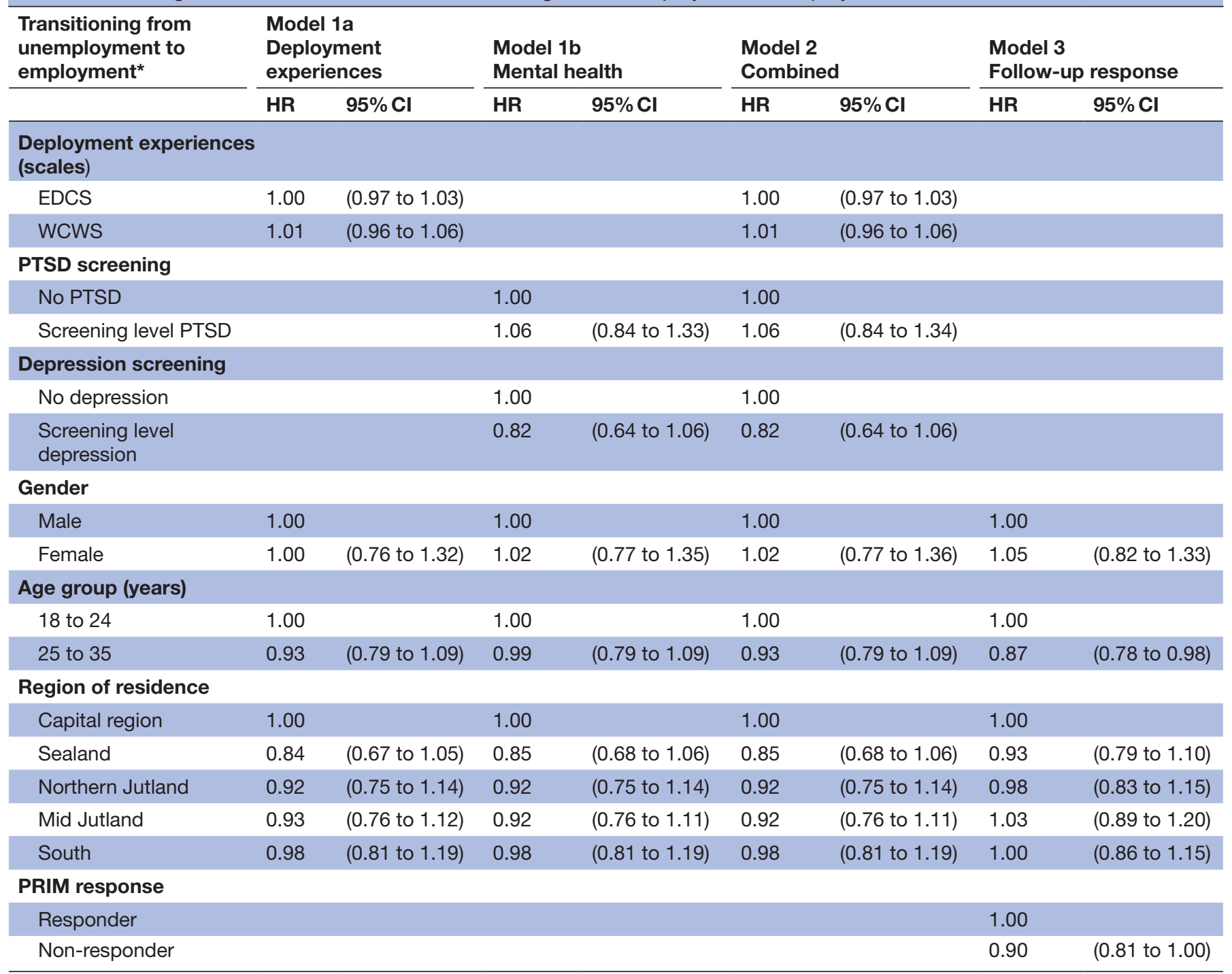

${ }^{*}$ All models are stratified by highest achieved education and time period (era).

EDCS, Exposure to Danger and Combat Scale; PRIM, Psychological Reactions following International Missions (questionnaire); PTSD, post-traumatic stress disorder; WCWS, Witnessing Consequences of War Scale.

time. Second, the systematic distribution of follow-up questionnaires across multiple years and missions allowed for inferences to be based on a population with diverse deployments. Furthermore, the main predictors were measured through validated scales on deployment experiences, PTSD and depression. However, several limitations must be addressed. First, in the context of the DREAM data used, employment is characterised by not receiving any public payments and thus being self-supporting. While this is an accepted method ${ }^{33}$ it does not rule out misclassification of the few persons who become self-supporting without having actual income from employment. Second, the PRIM questionnaire is typically filled in within 6 to 8 months after homecoming. However, we did not have the exact dates the soldiers filled out the PRIM, and consequently all dates were set to 6 months, which is the approximate time the PRIM questionnaire was first distributed to the FDS. Third, the non-significant findings in our study may relate to the effects of treatment that is offered by military psychologists based on the results of the PRIM questionnaire, as well as the help from social workers of the Danish Defence Veteran Centre, as this select treatment and social help may aid soldiers in gaining employment. This limits conclusions about the effects of mental health problems independent of treatment. Fourth, we did not know the reason for departure from the military. Previous studies have found higher levels of attrition from the military soldiers with mental health problems, ${ }^{38}$ and a relationship between different reasons for separation and odds of unemployment. ${ }^{8}$ However, our study could not account for any effect of differences in the reason for separation. Fifth, while the use of self-reported mental health problems is the general norm within this area of research, the potential under-reporting of disability 
when using self-reports as compared with more objective measures $^{39}$ may lower the contrast between those who responded to the PRIM. Finally, the setup, including the lack of information on the type of work and the desire and satisfaction of FDS with the type of employment does not allow us to judge the permanency of the positions gained when transitioning from unemployment.

\section{Comparison with previous studies}

The findings of this study regarding PTSD and depressive symptoms are in agreement with previous crosssectional $^{6711} 7^{13}$ and prospective studies ${ }^{814}$ conducted outside of treatment-seeking populations, which did not find PTSD, depression or deployment experiences to predict employment outcomes. Specifically, our results show that there are no overall differences among FDS in the probability of gaining employment when unemployed, based on PTSD and depression status as well as deployment experiences. Still, other cross-sectional studies $^{2}$ 5-7 910 and prospective studies ${ }^{4}$ have found such mental health problems to relate to employment outcomes. Furthermore, our findings on deployment experiences extends previous findings ${ }^{13} 1618$ on the relationship between combat and unemployment by showing that the level of exposure to possibly traumatic deployment events was not predictive of the probability of gaining employment. The differences between our null findings and the positive findings in other studies need to be addressed. While this study extends previous findings by studying differences in the dynamic transitions between employment and unemployment, it does not account for the opposite transitions (from employment to unemployment). Based on this setup, we therefore cannot rule out that PTSD and depression status as well as deployment experiences are predictors of an increased risk of being unemployed at single time points (eg, at 1 year post-deployment), as previous studies suggest. Still, the differences may also pertain to methodological differences. We find that a primary problem in the literature is the use of cross-sectional data; since unemployment may affect mental health negatively, ${ }^{9} 2122$ cross-sectional studies may inflate the relationship. Second, the use of outcomes sampled at a single time point allows for differences to coincidentally relate to the timing of assessment more than to the general risk of unemployment. Third, the differences found between our post 9/11 sample and samples from other periods may relate to the era of deployment, as several studies have documented major differences in how military service in different periods affect labour market attachment. ${ }^{16}{ }^{16-42}$

The non-existing relationship between mental health and unemployment has also been found in several treatment-seeking samples, ${ }^{35691012}$ where one would expect the contrasts between mental health status to be smaller. The difference between these results and our findings may be explained by the systematic non-response on our screening questionnaires. Thus, the use of registries allowed us to test the effect of non-response by including
3046 soldiers who did not have a corresponding PRIM follow-up. This finding suggests that non-responders may have a lower probability than responders to transition from unemployment to employment. Still these veterans may be among those seeking help and such an effect could add to a larger contrast in the help-seeking samples. Across response patterns, however, previous results on the present sample have suggested that FDS overall have a greater chance of gaining employment when unemployed than comparable non-FDS in the 5 years after homecoming. ${ }^{17}$

\section{Future directions}

Our results indicate that a systematic screening of deployment experiences, PTSD and depression symptoms 6 months after deployment, may be not useful to predict the ability to get employment among unemployed FDS. Further studies are, however, needed to determine if these factors predict transitioning from employment to unemployment. Future studies investigating predictors of labour market outcomes in the general population of (non-treatment seeking) FDS should also seek to account for treatment and help received by the veterans in the time until measurement of employment to account for treatment effects on employability. Also, while complicated, studies should seek to account for the effects of multiple deployments. Furthermore, our findings of a possible lowered probability of gaining employment among non-responders may question the ability of voluntary screenings to account for all of those in need of employment-related aid after military deployments. These results are also of clinical importance and may call for an increased early focus on veterans who may be in need of help, but do not respond to distributed screenings. Finally, while our study did not find PTSD and depression to be significant predictors, the resulting coefficients do suggest a stronger effect of depression than PTSD on remaining unemployed, which is consistent with the literature, ${ }^{8}$ and which may raise awareness about the possible differences in the effects of these mental health problems.

\section{CONCLUSION}

This study investigated deployment experiences and screening levels of post-deployment PTSD and depression as predictors of the probability of gaining employment when unemployed in Danish FDS with a single deployment behind them. We did not find such factors to be significant predictors of gaining employment in the time from 6 months to 5 years after homecoming. Nevertheless, increased awareness of and attention to veterans who do not respond to systematically distributed screenings may be needed, as it may be among them where we will find those most vulnerable, and with the lowest probability of gaining new employment if they become unemployed. 
Acknowledgements This study was supported by the Research and Knowledge Centre, The Danish Veteran Centre. The Centre had no formal role in designing, analysing, interpreting and writing of the manuscript or on the decision to submit the paper.

Contributors AFE: Contributed to the design of the study, data setup, analyses and writing of the paper. PMC: Contributed to the design of the study and writing of the paper. SBA: Contributed to the design of the study and writing of the paper. K-IK: Contributed to the design of the study and writing of the paper. MSV: Contributed to the design of the study and writing of the paper. JP: Contributed to the design of the study, data setup, analyses and writing of the paper.

Funding This study was supported by the Research and Knowledge Centre, The Danish Veteran Centre, with funding from the Danish government Finance Act of 2014.

\section{Competing interests None declared.}

Patient consent for publication Not required.

Provenance and peer review Not commissioned; externally peer-reviewed.

Data availability statement No data are available. The data used was hosted by Statistics Denmark and the analyses were conducted on de-identified records on Statistics Denmark's servers. These data are not publicly available.

Open access This is an open access article distributed in accordance with the Creative Commons Attribution Non Commercial (CC BY-NC 4.0) license, which permits others to distribute, remix, adapt, build upon this work non-commercially, and license their derivative works on different terms, provided the original work is properly cited, appropriate credit is given, any changes made indicated, and the use is non-commercial. See: http://creativecommons.org/licenses/by-nc/4.0/.

\section{ORCID iD}

Andreas Friis Elrond http://orcid.org/0000-0002-4888-2992

\section{REFERENCES}

1 Iversen A, Nikolaou V, Greenberg N, et al. What happens to British veterans when they leave the armed forces? Eur J Public Health 2005;15:175-84.

2 Pietrzak RH, Goldstein MB, Malley JC, et al. Subsyndromal posttraumatic stress disorder is associated with health and psychosocial difficulties in veterans of operations enduring freedom and Iraqi freedom. Depress Anxiety 2009;26:739-44.

3 Resnick SG, Rosenheck RA. Posttraumatic stress disorder and employment in veterans participating in veterans health administration compensated work therapy. J Rehabil Res Dev 2008;45:427-36.

4 Savoca E, Rosenheck R. The civilian labor market experiences of Vietnam-era veterans: the influence of psychiatric disorders. J Ment Health Policy Econ 2000;3:199-207.

5 Smith MW, Schnurr PP, Rosenheck RA. Employment outcomes and PTSD symptom severity. Ment Health Serv Res 2005;7:89-101.

6 Cohen SI, Suri P, Amick MM, et al. Clinical and demographic factors associated with employment status in US military veterans returning from Iraq and Afghanistan. Work 2013;44:213-9.

7 Hamilton AB, Williams L, Washington DL. Military and mental health correlates of unemployment in a national sample of women veterans. Med Care 2015;53:S32-8.

8 Horton JL, Jacobson IG, Wong CA, et al. The impact of prior deployment experience on civilian employment after military service. Occup Environ Med 2013;70:408-17.

9 Zivin K, Campbell DG, Lanto AB, et al. Relationships between mood and employment over time among depressed Va primary care patients. Gen Hosp Psychiatry 2012;34:468-77.

10 Zivin K, Yosef M, Levine DS, et al. Employment status, employment functioning, and barriers to employment among Va primary care patients. J Affect Disord 2016;193:194-202.

11 Amick MM, Meterko M, Fortier CB, et al. The deployment trauma phenotype and employment status in veterans of the wars in Iraq and Afghanistan. J Head Trauma Rehabil 2018;33:E30-40.

12 Adler DA, Possemato K, Mavandadi S, et al. Psychiatric status and work performance of veterans of operations enduring freedom and Iraqi freedom. Psychiatr Serv 2011;62:39-46.

13 Burnett-Zeigler I, Valenstein M, Ilgen M, et al. Civilian employment among recently returning Afghanistan and Iraq national guard veterans. Mil Med 2011;176:639-46.

14 Erbes CR, Kaler ME, Schult T, et al. Mental health diagnosis and occupational functioning in national Guard/Reserve veterans returning from Iraq. J Rehabil Res Dev 2011;48:1159-70.
15 Karstoft K-I, Armour C, Andersen SB, et al. Community integration after deployment to Afghanistan: a longitudinal investigation of Danish soldiers. Soc Psychiatry Psychiatr Epidemiol 2015;50:653-60.

16 Maclean A. The things they carry: combat, disability and unemployment among US men. Am Sociol Rev 2010;75:563-85.

17 Elrond A, Stoltenberg C, Nissen L, et al. Labor market affiliation after deployment: Danish soldiers fare well, but face increased risk of long-term sickness absence when returning from Afghanistan. Scand $J$ Work Environ Health 2019;45:289-97.

18 Burdett H, Fear NT, MacManus D, et al. Unemployment and benefit claims by UK veterans in the new millennium: results from a record linkage study. Occup Environ Med 2019;76:726-32.

19 Andersen SB, Karstoft K-I, Bertelsen M, et al. Latent trajectories of trauma symptoms and resilience: the 3-year longitudinal prospective USPER study of Danish veterans deployed in Afghanistan. J Clin Psychiatry 2014;75:1001-8.

20 Humensky JL, Jordan N, Stroupe KT, et al. How are Iraq/AfghanistanEra veterans faring in the labor market? Armed Forces \& Society 2012.

21 Paul KI, Moser K. Unemployment impairs mental health: metaanalyses. J Vocat Behav 2009;74:264-82.

22 Wanberg CR. The individual experience of unemployment. Annu Rev Psychol 2012;63:369-96.

23 Fear NT, Van Staden L, Iversen A, et al. 50 ways to trace your veteran: increasing response rates can be cheap and effective. Eur $J$ Psychotraumatol 2010;1:5516.

24 Littman AJ, Boyko EJ, Jacobson IG, et al. Assessing nonresponse bias at follow-up in a large prospective cohort of relatively young and mobile military service members. BMC Med Res Methodol 2010;10:99.

25 Lyk-Jensen SV, Heidemann J, Glad A, et al. Returned Danish Soldiers: The soldiers psychological healthprofile before and after deployment [Danske hjemvendte soldater: soldaternes psykiske sundhedsprofil før og efter udsendelse]. SFI - Det Nationale Forskningscenter for Velfærd, 2012.

26 Nissen LR, Stoltenberg C, Nielsen ABS, et al. Danish Gulf War veterans revisited: no evidence of increased sickness absence or reduced labor market outcome after deployment to the Persian Gulf. Mil Med 2016;181:1644-9. doi:10.7205/MILMED-D-15-00534

27 Karstoft K-I, Andersen SB, Nielsen ABS. Assessing PTSD in the military: validation of a scale distributed to Danish soldiers after deployment since 1998. Scand J Psychol 2017;58:260-8.

28 Burr H, Pedersen J, Hansen JV. Work environment as predictor of long-term sickness absence: linkage of self-reported DWECS data with the DREAM register. Scand J Public Health 2011;39:147-52.

29 Karstoft K-I, Nielsen ABS, Nielsen T. Assessment of depression in veterans across missions: a validity study using Rasch measurement models. Eur J Psychotraumatol 2017;8:1326798.

30 Nissen LR, Karstoft K-I, Vedtofte MS, et al. Low-Level cognitive ability in young adulthood and other risk factors of depression in an observational cohort study among deployed Danish soldiers. Soc Psychiatry Psychiatr Epidemiol 2019;54:497-506.

31 Karstoft K-I, Nielsen T, Nielsen ABS. Perceived danger during deployment: a Rasch validation of an instrument assessing perceived combat exposure and the witnessing of combat consequences in a war zone. Eur J Psychotraumatol 2018;9:1487224.

32 Christensen KB, Andersen PK, Smith-Hansen L, et al. Analyzing sickness absence with statistical models for survival data. Scand $J$ Work Environ Health 2007;33:233-9.

33 Pedersen J, Bjorner JB, Burr H, et al. Transitions between sickness absence, work, unemployment, and disability in Denmark 20042008. Scand J Work Environ Health 2012;38:516-26.

34 Hansen SM, Hetland ML, Pedersen J, et al. Effect of rheumatoid arthritis on longterm sickness absence in 1994-2011: a Danish cohort study. J Rheumatol 2016;43:707-15.

35 Statistics Denmark. Net unemployed by sex and persons/pct. StatBank Denmark - data and statistics (2001-2017). Available: https://www.statistikbanken.dk/statbank5a/SelectVarVal/ saveselections.asp [Accessed 20 May 2018].

36 Therneau TM. A package for survival analysis in S, 2015. Available: https://CRAN.R-project.org/package=survival [Accessed 12 Feb 2018].

37 Rytwinski NK, Scur MD, Feeny NC, et al. The co-occurrence of major depressive disorder among individuals with posttraumatic stress disorder: a meta-analysis. J Trauma Stress 2013;26:299-309.

38 Hoge CW, Auchterlonie JL, Milliken CS. Mental health problems, use of mental health services, and attrition from military service after returning from deployment to Iraq or Afghanistan. JAMA 2006;295:1023-32.

39 Griffin CL, Stein MA. Self-perception of disability and prospects for employment among U.S. veterans. Work 2015;50:49-58. 
40 Angrist JD. Estimating the labor market impact of voluntary military service using social security data on military applicants. Econometrica 1998;66:249.
41 MacLean A, Elder GH. Military service in the life course. Annu Rev Sociol 2007;33:175-96.

42 Teachman JD, Call VRA. The effect of military service on educational, occupational, and income attainment. Soc Sci Res 1996;25:1-31. 